\title{
Long-Tailed Macaque Response to Deforestation in a Plasmodium knowlesi-Endemic Area
}

\author{
Danica J. Stark (iD, ${ }^{1,2}$ Kimberly M. Fornace, ${ }^{3}$ Patrick M. Brock, ${ }^{4}$ Tommy Rowel Abidin, ${ }^{5}$ \\ Lauren Gilhooly, ${ }^{6}$ Cyrlen Jalius, ${ }^{2,7}$ Benoit Goossens, ${ }^{1,2,8,9}$ Chris J. Drakeley, ${ }^{3}$ \\ and Milena Salgado-Lynn ${ }^{1,2,7,9}$ \\ ${ }^{1}$ Organisms and Environment Division, Cardiff School of Biosciences, Cardiff University, Sir Martin Evans Building, Museum Avenue, \\ Cardiff CF10 3AX, UK \\ ${ }^{2}$ Danau Girang Field Centre, c/o Sabah Wildlife Department, Wisma Muis Block B Floor 5, 88100 Kota Kinabalu, Sabah, Malaysia \\ ${ }^{3}$ Faculty of Infectious and Tropical Diseases, London School of Hygiene and Tropical Medicine, London, UK \\ ${ }^{4}$ Institute of Biodiversity, Animal Health and Comparative Medicine, College of Medical, Veterinary and Life Sciences, University of Glasgow, \\ Glasgow G61 1QH, UK \\ ${ }^{5}$ Infectious Diseases Society Kota Kinabalu-Menzies School of Health Research Clinical Research Unit, Kota Kinabalu, Malaysia \\ ${ }^{6}$ Department of Anthropology, Faculty of Social Sciences, University of Western Ontario, Social Science Building, London N6A 3K7, Canada \\ ${ }^{7}$ Wildlife Health, Genetic and Forensic Laboratory, Sabah Wildlife Department, Wisma Muis, 88100 Kota Kinabalu, Sabah, Malaysia \\ ${ }^{8}$ Sabah Wildife Department, Wisma Muis, 88100 Kota Kinabalu, Sabah, Malaysia \\ ${ }^{9}$ Sustainable Places Research Institute, Cardiff University, 33 Park Place, Cardiff CF10 3BA, UK
}

Abstract: Land-use changes can impact infectious disease transmission by increasing spatial overlap between people and wildlife disease reservoirs. In Malaysian Borneo, increases in human infections by the zoonotic malaria Plasmodium knowlesi are hypothesised to be due to increasing contact between people and macaques due to deforestation. To explore how macaque responses to environmental change impact disease risks, we analysed movement of a GPS-collared long-tailed macaque in a knowlesi-endemic area in Sabah, Malaysia, during a deforestation event. Land-cover maps were derived from satellite-based and aerial remote sensing data and models of macaque occurrence were developed to evaluate how macaque habitat use was influenced by land-use change. During deforestation, changes were observed in macaque troop home range size, movement speeds and use of different habitat types. Results of models were consistent with the hypothesis that macaque ranging behaviour is disturbed by deforestation events but begins to equilibrate after seeking and occupying a new habitat, potentially impacting human disease risks. Further research is required to explore how these changes in macaque movement affect knowlesi epidemiology on a wider spatial scale.

Keywords: Deforestation, Remote sensing, Habitat selection, Malaria, Borneo, GPS collar

Danica J. Stark and Kimberly M. Fornace: Joint first authors.

Electronic supplementary material: The online version of this article (https://doi. org/10.1007/s10393-019-01403-9) contains supplementary material, which is available to authorized users.

Published online: March 29, 2019

Correspondence to: Benoit Goossens, e-mail: GoossensBR@cardiff.ac.uk

\section{INTRODUCTION}

Deforestation and associated habitat disturbance have been associated with changing infectious disease transmission by bringing wildlife disease reservoirs into closer proximity to 
people (Patz et al. 2004). This response to habitat loss is particularly relevant for non-human primates, as an estimated $90 \%$ of all primate species live in tropical areas and depend on forests that are rapidly disappearing (Chapman and Peres 2001). Within Malaysian Borneo, the increased detection of the zoonotic malaria Plasmodium knowlesi (henceforth knowlesi) in humans is hypothesised to be driven by increasing spatial overlap between human populations and simian hosts (Imai et al. 2014).

Large numbers of human knowlesi infections were only identified in 2004 in Malaysian Borneo (Singh et al. 2004). Since then, human knowlesi infections have been identified throughout Southeast Asia and knowlesi is now the main cause of clinical malaria in Malaysia (William et al. 2013; Shearer et al. 2016). Changes in the numbers and proportions of suspected knowlesi case notifications within the Malaysian state of Sabah suggest that incidence of the disease is increasing (William et al. 2013). In Sarawak, Malaysia, knowlesi has been found in wild long-tailed and pig-tailed macaques (Macaca fascicularis and M. nemestrina) (Lee et al. 2011); however, genetic studies of macaque and human parasites suggest knowlesi remains primarily a zoonosis, with macaques acting as reservoir hosts (Lee et al. 2011; Divis et al. 2015).

Land-use changes are believed to be the primary driver of this apparent emergence. In Northern Sabah, Malaysia, an area undergoing rapid environmental change through conversion of forest to agricultural land, deforestation has been associated with increases in reported incidence of knowlesi; however, the mechanisms underlying this association remain unknown (Fornace et al. 2016). While changes in forest cover affect the abundance of mosquito vectors and new settlements can increase the number of people at risk, a key determinant of risk is the proximity and infection status of macaque populations to susceptible individuals (Imai et al. 2014). Within this area of Sabah, a recent case control study found individuals reporting proximity to macaques in the previous month had over three times the odds of knowlesi infection (Grigg et al. 2017).

As the geographical range of long-tailed macaques is one of the most widespread ranges of non-human primates (Fooden 1995), and due to the rapid rate at which forest is being cleared within their natural range in Southeast Asia, many long-tailed macaque populations are now largely ecologically associated with humans (Sha et al. 2009; Fuentes 2011; Moyes et al. 2016). Although long-tailed macaques are flexible in their feeding strategies, and able to adapt to changing environments (Menard 2004; Gumert 2011), how they adjust their ranging patterns during periods of disturbance in their home range is not well understood. Primates are generally known to be able to create a cognitive map that allows them to travel efficiently between food patches (Janson and Byrne 2007). Whether their home ranges are within forests or urban areas, their familiarity within the area results in relatively stable home ranges (Milton and May 1976). However, when the habitat within their spatial memory map is changed, the ability to adjust and/or re-establish a new cognitive map is important for such a species in a changing environment.

To explore how macaque's response to environmental changes may contribute to human disease risks, we analysed movement data of a long-tailed macaque that was GPS-collared prior to a deforestation event in close proximity to a human settlement in a knowlesi-endemic area of Northern Sabah. We aimed to (1) examine how ranging patterns changed throughout the deforestation event and (2) evaluate how the predictability of macaque habitat selection was influenced by the deforestation and disturbance.

\section{Methods}

\section{Study Site}

This study was conducted in a largely deforested and highly fragmented case study area in Kudat district in Sabah, Malaysia (N6.77, E116.78, 10-150 $\mathrm{m}$ above sea level, Fig. 1). The site was selected as a representative area where knowlesi transmission is occurring based on household locations of symptomatic cases recruited at district hospitals (Grigg et al. 2017) and is the focus of a number of linked interdisciplinary studies on knowlesi ecology, including entomological, sociological and epidemiological studies (http://malaria.lshtm.ac.uk/MONKEYBAR). This area includes 11 villages with a total population of 1160 individuals and had a knowlesi incidence of 12 cases per 1000 individuals in 2014 (Fornace et al. in press). High densities of Anopheles balabacensis have been reported in settled and agricultural lands in this site, and mosquitoes infected by knowlesi and other simian malarias have been identified (Wong et al. 2015; Manin et al. 2016). This is a low elevation, coastal area dominated by small-scale agri- 


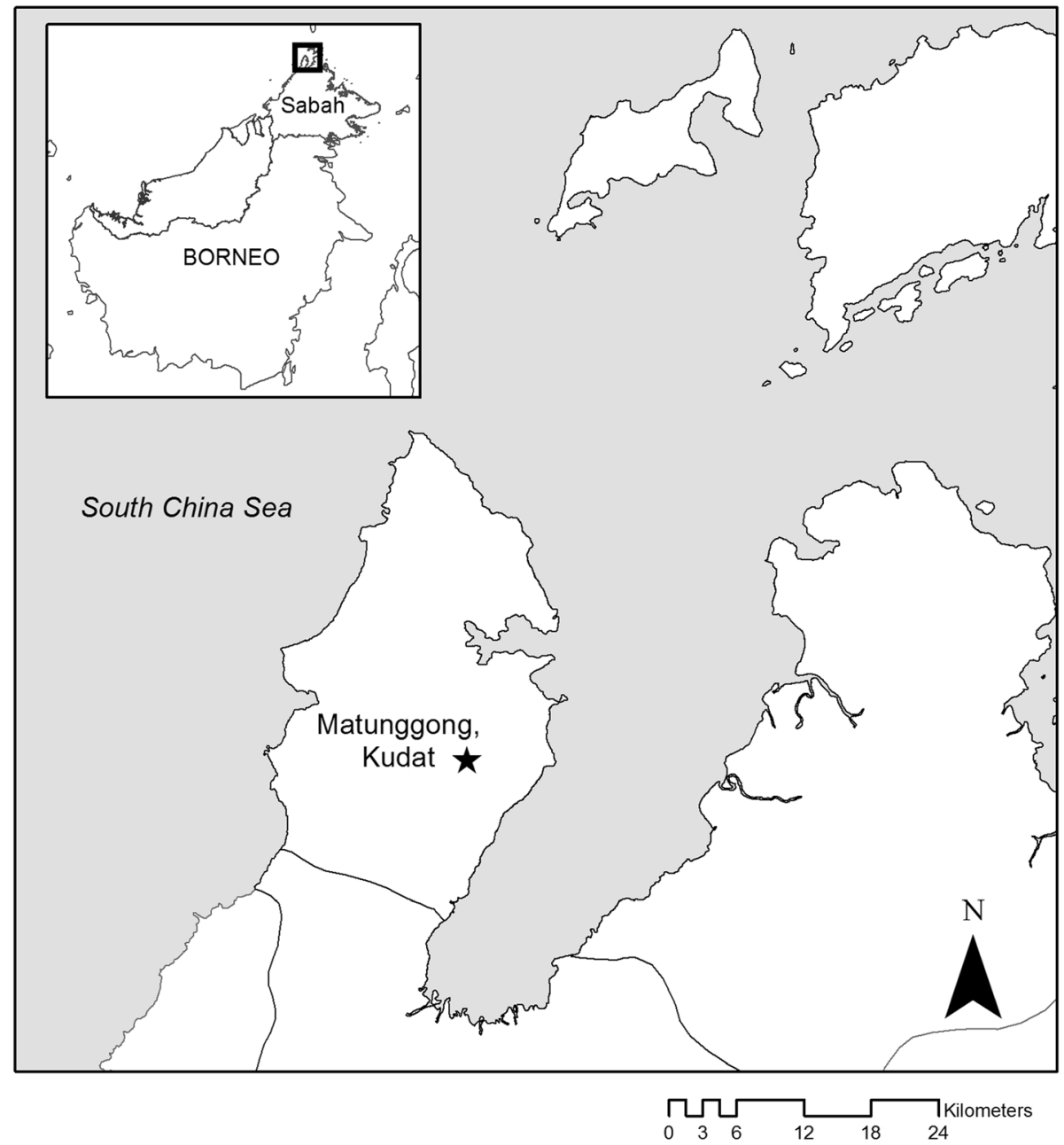

Figure 1. Map showing study site in Kudat, Sabah, Malaysian Borneo. Star indicates where the long-tailed macaque was collared and the clearing occurred during the study period.

culture, including swidden farming and small rubber and oil palm plantations. There are high rates of land-use change and, during the study period, large-scale forest clearing for a rubber plantation. Land-cover maps were derived from Landsat and aerial imagery for six periods corresponding to stages of deforestation that occurred during this study (Fig. 2). The deforestation event refers to the entire study period whereby forest loss was being observed. The deforestation event was divided into six periods, which included a pre-clearing (Period 1) and postclearing (Period 6) stage. Although there may have been some clearing going on during the pre- and post-clearing periods, it was outside of our main study area and therefore not considered. The periods of active land clearing were divided based on a combination of the imagery available from the Landsat and aerial flights and ensuring there were sufficient numbers of GPS fixes for home range estimation (Benhamou and Cornelis 2010).

\section{Macaque Collaring and Sampling}

An adult male long-tailed macaque was caught in a baited trap and was sedated by an authorised veterinarian in February 2014. A VHF/GPS remote-download, automatic self-releasing collar (Telemetry Solutions Quantum 4000E) was fitted, which weighed $\sim 2.5 \%$ of the individual's body mass [cf. recommended 5\% maximum (American Society of Mammalogists 1998)]. The collar was pre-programmed to record data points every $30 \mathrm{~min}$ from 05:00 to 07:00 and 17:00 to 19:00, and every other hour between these times of the day, automatically releasing after 169 days. While the animal was sedated, $2 \mathrm{ml}$ of blood was collected in an 

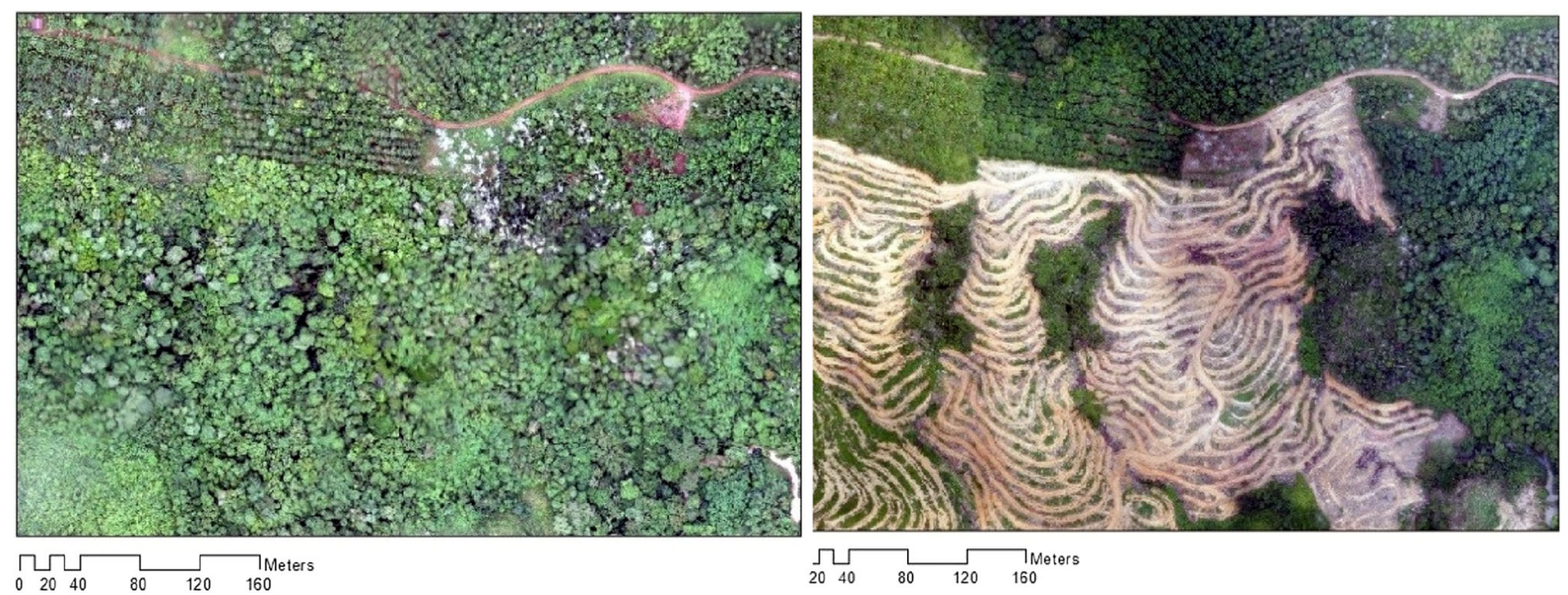

Figure 2. Examples of aerial imagery collected by UAV pre- and post-deforestation within the study area.

EDTA-containing tube and kept refrigerated until processing (Supplementary Material).

At the time of collaring, the macaque belonged to an unhabituated group that typically fled upon seeing humans. No effort was made to habituate the group in order to ensure that the home range data were not affected by researcher presence. Group size was therefore estimated using auditory cues from macaque movement in the trees since visual sightings were rare. The movement of one individual is often used as a proxy for primate troop movements (e.g. Ren et al. 2009; McLean et al. 2016; Stark et al. 2017), and this assumption was validated by visual and auditory cues during field surveys; therefore, the locations of the collared individual were considered representative of the group as a whole.

\section{Home Range Estimation}

To calculate home range estimates and examine shifts in range and movement rates over the different clearing periods, biased random bridges (BRB) were used (Benhamou 2011; Stark et al. 2017). The maximum time threshold $\left(T_{\max }\right)$, the longest period between points before they are no longer autocorrelated, was set to $7200 \mathrm{~s}$. Based on the average distances between fixes during static collar tests, the length threshold of movement $\left(L_{\min }\right)$ was set to $15 \mathrm{~m}$. This assumed that tracks less than $L_{\min }$ were assumed resting or due to GPS error. The minimum smoothing parameter $\left(H_{\min }\right)$ was set at $25 \mathrm{~m}$, which was large enough to encompass all potential locations the animal could occur within while being recorded at the same location, while not being larger than half the mean distance travelled for the time $T_{\max }$. Diffusion rates were estimated for each land-use type using the land-cover map. The utilisation distributions (UDs) were based on the 90th percentile for overall home range size and 50th percentile for the core area.

\section{Habitat Use Modelling}

To test whether macaque habitat use within a $1000 \mathrm{~m}$ range was influenced by the deforestation event, binomial generalised additive models (GAMs) were fitted to eight habitat variables for each of the six time periods. Habitat variables were: aspect, slope, elevation, distance to nearest road, distance to nearest house, distance to nearest forest, distance to nearest agriculture and distance to nearest clearing (at $30 \mathrm{~m}^{2}$ resolution). For each period, the same number of absence points as there were presence points were randomly sampled from an area within $1000 \mathrm{~m}$ from all included presence points. Absence points were re-sampled 100 times for each period, and models run on each of these data sets.

To explore whether macaque habitat use was influenced by the disturbance of deforestation during periods of active land clearing, binomial generalised additive models fitted as above to periods 3,4 and 5 , but with an additional variable: distance to recent deforestation (i.e. between periods 2 and 3, 3 and 4, and 4 and 5, respectively). All statistical analyses and land-cover classification were conducted in R statistical software (R Foundation for Statistical Computing, Vienna, Austria). Maps were visualised using ArcGIS (ESRI, Redlands, USA). 


\section{Results}

\section{Macaque Troop Size and Knowlesi Infection}

The collared animal was found PCR positive for Plasmodium spp., specifically knowlesi. Obtaining an accurate group size estimate both pre- and post-clearing was difficult due to the skittish and elusive nature of this unhabituated macaque group, but was estimated at $\geq 40$ individuals near the time of collaring, and fell to $\sim 20$ individuals following the deforestation, suggesting a group fission event may have occurred.

\section{Land-Cover Changes and Macaque Ranging Behaviours}

Between February and September 2014, a total of 190 ha were cleared within a $1000 \mathrm{~m}$ buffer area around the macaque troop home range (Table 1). This included a loss of 95.5 ha of secondary forest, representing $14 \%$ of the available secondary forest within this home range area. The home range and core range of the collared individual declined in area as the clearing progressed, with the core area decreasing from 10.3 ha prior to the clearing to less than 6 ha after the clearing was completed (Fig. 3). The pro- portion of time the macaque spent in forested areas vs other habitats also changed as clearing progressed, with the ratio of points in the forest to non-forest dropping during peak clearing periods (pre-clearing: 2.69, peak clearing: 0.93 and up to 6.38 post-clearing). There was an increase in fixes in farmland/agricultural lands during the peak clearing periods, from $25 \%$ of the points in Period 1 to $41 \%$ in Period 3, and then dropped down to $9 \%$ after the major clearing had finished (Period 6). Diffusion rates further suggest that the macaque moved through non-forest areas faster during the peak periods of forest clearing (Periods 3 , 4 and 5).

\section{Macaque Habitat Use}

Binomial generalised additive models fit separately across periods suggest varying associations between macaque occurrence and habitat characteristics. The median proportion of deviance explained by 100 models fit for each period decreases as clearing begins and then increases following the main clearing activities (Fig. 4). When distance from recent deforestation was included in models during peak clearing periods, the strongest association between distance from deforestation and macaque occurrence occurred during Period 4 (i.e. in response to forest loss be-

Table 1. Land-Use Change and Macaque Ranging Characteristics.

\begin{tabular}{|c|c|c|c|c|c|c|}
\hline & $\begin{array}{l}\text { Period } 1 \\
\text { Before } \\
\text { clearing }\end{array}$ & $\begin{array}{l}\text { Period } 2 \\
\text { March-April } \\
2014\end{array}$ & $\begin{array}{l}\text { Period } 3 \\
\text { May-June } \\
2014 \\
\end{array}$ & $\begin{array}{l}\text { Period } 4 \\
\text { June-July } \\
2014\end{array}$ & $\begin{array}{l}\text { Period } 5 \\
\text { July-Aug } \\
2014\end{array}$ & $\begin{array}{l}\text { Period } 6 \\
\text { After } \\
\text { clearing } \\
\end{array}$ \\
\hline \multicolumn{7}{|l|}{ Land-use characteristics } \\
\hline Forest area (ha) & 669.5 & 664.6 & 646.9 & 610.5 & 574.0 & 574.0 \\
\hline Core forest area excluding edges (ha) & 335.6 & 328.5 & 315.4 & 294.1 & 273.8 & 273.8 \\
\hline Cleared/open areas (ha) & 192.9 & 201.2 & 248.2 & 318.1 & 382.5 & 382.5 \\
\hline Net forest loss (ha) & - & 5.0 & 22.6 & 59.0 & 95.5 & 95.5 \\
\hline Cumulative proportion area cleared (\%) & - & $0.6 \%$ & $4.0 \%$ & $9.1 \%$ & $13.7 \%$ & $13.7 \%$ \\
\hline \multicolumn{7}{|l|}{ Macaque ranging } \\
\hline Home range size (ha) & 38.53 & 44.69 & 36.38 & 44.31 & 36.50 & 25.85 \\
\hline Core range size (ha) & 10.29 & 11.98 & 9.69 & 9.97 & 8.24 & 5.67 \\
\hline Distance from houses (median-m) & 310.3 & 284.5 & 248.8 & 285.0 & 346.7 & 421.6 \\
\hline Diffusion rate (global) $\left(\mathrm{m}^{2} / \mathrm{s}\right)$ & 1.52 & 1.13 & 0.97 & 2.78 & 2.46 & 0.81 \\
\hline Forest & 1.08 & 0.60 & 0.55 & 0.52 & 0.65 & 0.35 \\
\hline Farmland & 0.14 & 0.15 & 0.58 & 0.30 & - & - \\
\hline Clearing & - & - & 0.18 & - & - & - \\
\hline
\end{tabular}



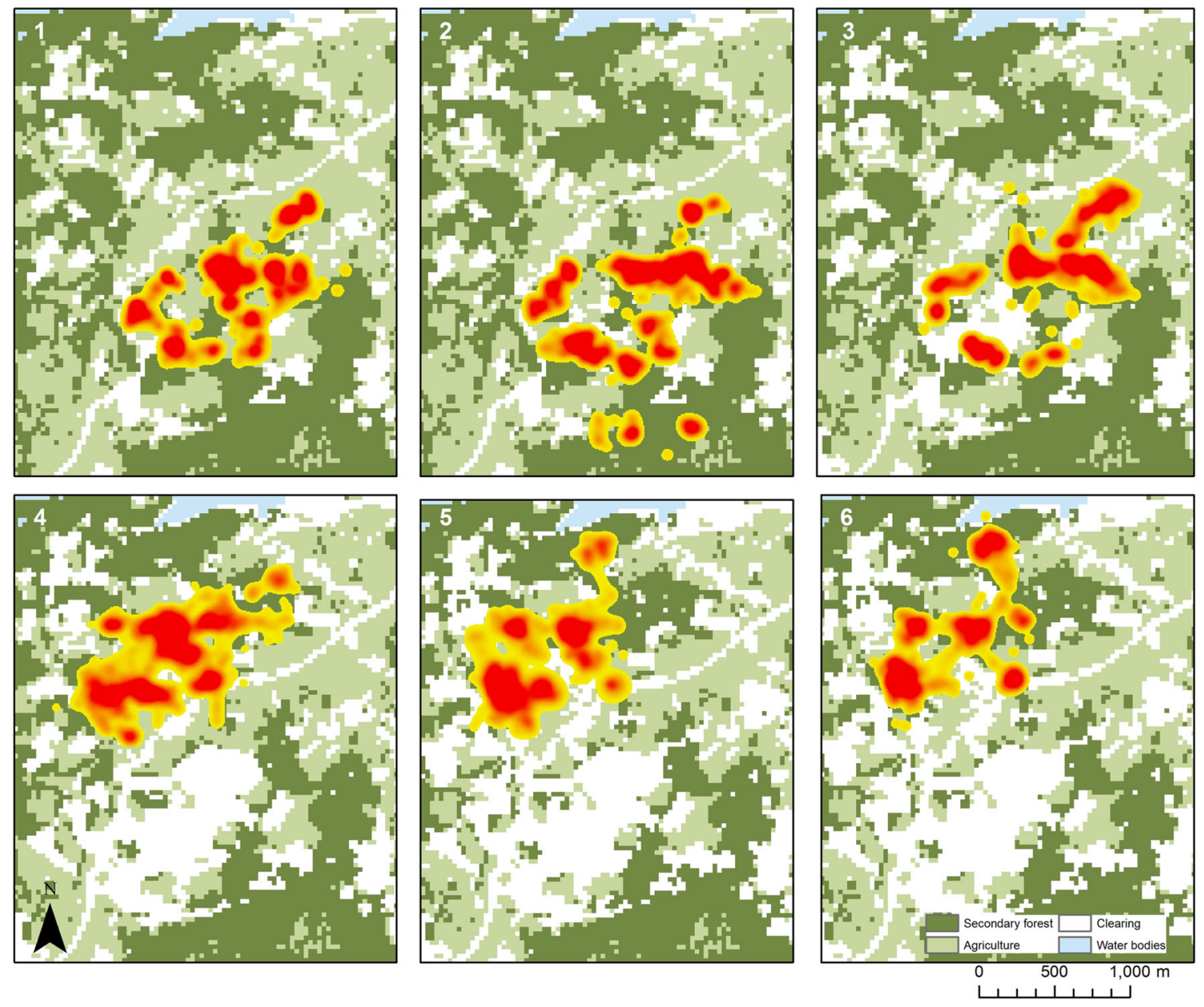

Figure 3. Utilisation distributions and estimated home ranges (ha) for the collared macaque. Time periods for clearing events: (1) February 2014, (2) March-April 2014, (3) April-May 2014, (4) May-June 2014, (5) June-August 2014 and (6) August-October 2014.
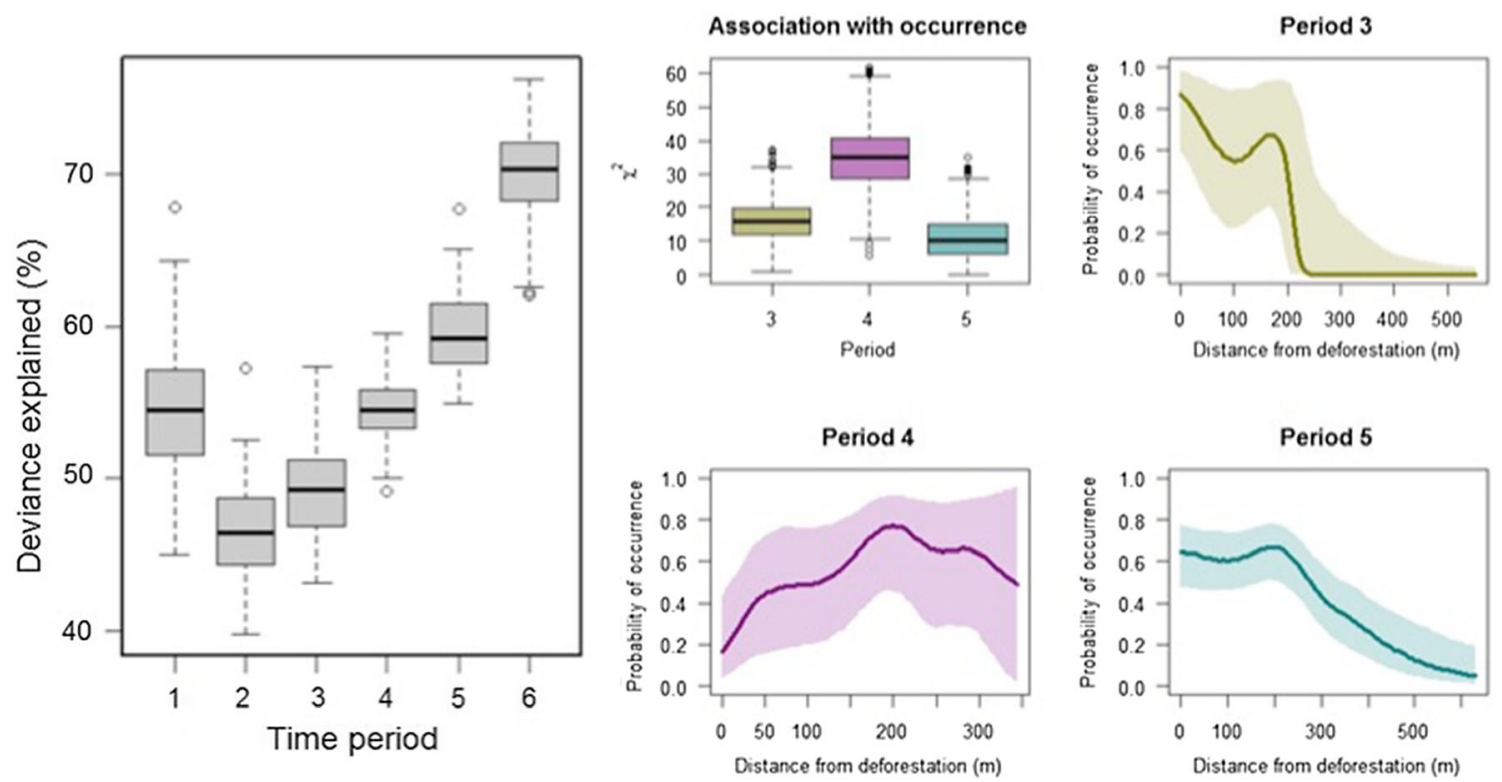

Figure 4. Deviance explained by 100 binomial generalised additive models fit for each time period (left), and associations between the probability of occurrence and distance to recent deforestation for peak clearing periods (right). 
tween Periods 3 and 4), with every model suggesting a strong effect, and the fitted curve suggesting avoidance relative to other periods (Fig. 4). The next strongest association occurred during Period 3, with approximately $80 \%$ of models suggesting a significant association, and the association was weakest during Period 5, with only 50\% of models suggesting a significant association.

\section{DIsCUSSION}

Although these data only represent a single macaque troop, results are consistent with the hypothesis that macaque ranging behaviour is disturbed by deforestation events, but begins to equilibrate after the troop seeks a new suitable habitat and moves to occupy it. During a large-scale clearing over a period of several months, changes were observed in the macaque troop group size, home range size, movement speeds and use of different habitat types. Statistical evidence indicates deforestation influenced the behaviour of macaques for this troop, which could be important in understanding how deforestation impacts knowlesi transmission.

Changes in group size may be due to a fluid fissionfusion social structure, especially in response to resource stress and habitat disturbance reported in some primate species [e.g. Ateles geoffroyi (Rodrigues 2017); Varecia variegata (Holmes et al. 2016)], although long-term data on this are scarce. After a severe forest fires in Kalimantan, macaques adjusted to low fruit and flower availability by relying on fallback foods (e.g. insects), by foraging in a more dispersed group, and by increasing the amount of time spent travelling on the ground (Berenstain 1986). It seems likely that the macaques in the current study responded to a drastic reduction in resource availability by splitting into two or more groups. Further long-term monitoring of macaques after complete deforestation events is necessary to determine whether such changes in group size are permanent.

While these models cannot be used to extrapolate to macaque distribution and habitat selection broadly, within this range, macaque occurrence during periods of active deforestation was associated with distance from recent clearing, suggesting avoidance of logging activities. Similar changes to home range and behaviour have been reported in other primate species in response to selective logging (e.g. Johns 1986) and initial decreases in M. fascicularis populations have been reported from selectively logged areas in Malaysian Borneo (Brodie et al. 2014). Variations in deviance explained by habitat models for each period suggest movements become less predictable during times of active clearing before returning closer to equilibrium once deforestation activities are completed (Fig. 4). Changes to macaque habitat and home range may have implications for infectious disease transmission, for example by bringing primates into closer proximity to people (e.g. Chapman et al. 2006; current study), or increasing population density in smaller forest fragments leading to higher contact rates between primates (e.g. Chapman et al. 2005). These anthropogenic land-use changes may additionally alter ecological community composition, vector breeding sites or human use of different environments, leading to further changes in disease risks (Young et al. 2013; Lambin et al. 2010). Furthermore, an increase in physiological and psychological stress can lead to macaques becoming immunocompromised, and thereby increasing macaque morbidity and mortality (Nunn and Altizer 2006).

Blood taken from the macaque at the time of collaring was positive for knowlesi. Although samples were not collected from the same animal in subsequent occasions nor from other members of the same troop, estimates of trooplevel Plasmodium prevalence within other troops in the Kudat district were 87\% (CI 67-98\%) (MSL, unpublished data). During the period of deforestation, 15 human cases of knowlesi were reported within $3 \mathrm{~km}$ of the macaque roosting sites, with the highest number of cases reported in June through July (Grigg et al. 2017). All cases were reported in adults (age range 19-59), and the majority were male (12/15). While it is impossible to determine whether these cases were related to changes in macaque movement, these observations are consistent with the possibility that the spike in human cases arose due to a knock-on effect of deforestation and therefore merits further investigation.

\section{CONCLUSION}

Despite efforts to collar additional troops in the area, attempts to collar additional macaques in this agricultureforest matrix were unsuccessful and may itself be an example of how land development impacts the distribution and behaviour of primates. However, these results indicate changes to macaque behaviour and space use in response to anthropogenic environmental change. Future work should include increasing the number of groups or individuals collared, in order to better understand the macaques' re- 
sponse to habitat clearing. However, it is difficult to obtain these data (including pre-, peak- and post-clearing movement data), as forest clearing plans are not always made known to others or done legally. These findings have important implications for understanding the epidemiology of knowlesi and other zoonotic diseases carried by longtailed macaques (e.g. helminth infections, simian foamy virus and herpes B) and should be explored further through more extensive studies or mathematical modelling approaches.

\section{ACKNOWLEDGEMENTS}

The authors would like to thank Dr Timothy William, Albert M Lim (Infectious Diseases Society Sabah), Beth Downe (London School of Hygiene and Tropical Medicine), Daniel bin Robot, Jesrine bin Binsu, Rhys White and Charlotte Defolie (Danau Girang Field Centre) for all their help with fieldwork and logistics, as well as to Dr Sergio GuerreroSánchez, Raziman, Jeffday Bin Jacobli and the Wildlife Rescue Unit for their assistance during the collaring process. The authors' appreciation is also to Kim Piera and Dr Nick Anstey (Menzies School of Health Research) for providing the P. knowlesi PCR positive control. The authors acknowledge the Medical Research Council, Natural Environmental Research Council, Economic and Social Research Council and Biotechnology and Biosciences Research Council for the funding received for this project through the Environmental and Social Ecology of Human Infectious Diseases Initiative (ESEI). Grant number: G1100796.

\section{COMPLIANCE WITH ETHICAL STANDARDS}

CONFLICT OF INTEREST The authors declare that they have no conflict of interest.

ETHICS All applicable institutional and/or national guidelines for the care and use of animals were followed. All macaque handling was carried out in accordance with the current laws of Malaysia and Sabah Wildlife Department's Standard Operation Procedures on Animal Capture, Anaesthesia and Welfare. Permission for macaque sampling was granted by the Sabah Wildlife Department, the Sabah Biodiversity Council and the London School of Hygiene and Tropical Medicine's Animal Welfare and Ethical Review Board. The macaque work carried out during this study was in accordance with the Weatherall report and followed the guidelines for non-human primates as described by Unwin et al. (2011). All efforts were made to ensure the welfare and reduce stress of the animals, with the addition of full personal protective equipment worn by all team members throughout the process to prevent human primate disease transmission.

\section{Open Access}

This article is distributed under the terms of the Creative Commons Attribution 4.0 International License (http://crea tivecommons.org/licenses/by/4.0/), which permits unrestricted use, distribution, and reproduction in any medium, provided you give appropriate credit to the original author(s) and the source, provide a link to the Creative Commons license, and indicate if changes were made.

\section{REFERENCES}

American Society of Mammalogists. 1998. 'Guidelines for the capture, handling and care of mammals as approved by the American Society of Mammalogists', Journal of Mammalogy, 74.

Benhamou S (2011) Dynamic approach to space and habitat use based on biased random bridges. PLoS One 6:e14592

Benhamou S, Cornelis D (2010) Incorporating movement behavior and barriers to improve kernel home range space use estimates. J Wildlife Management 74:1353-1360

Berenstain, L. 1986. 'Responses of Long-Tailed Macaques to Drought and Fire in Eastern Borneo: A Preliminary Report', Biotropica, 18.

Brodie JF, Giordano AJ, Zipkin EF, Bernard H, Mohd-Azlan J, Ambu L (2014) Correlation and persistence of hunting and logging impacts on tropical rainforest mammals. Conservation Biology 29:110-121

Chapman CA, Gillespie TR, Speirs ML (2005) Parasite prevalence and richness in sympatric colobines: effects of host density. American Journal of Primatology 67:259-266

Chapman CA, Peres CA (2001) Primate conservation in the new millennium: the role of scientists. Evolutionary Anthropology 10:16-33

Chapman CA, Speirs ML, Gillespie TR, Holland T, Austad KM (2006) Life on the edge: gastrointestinal parasites from the forest edge and interior primate groups. American Journal of Primatology 68:397-409

de Ruiter JR, Geffen E (1998) Relatedness of matrilines, dispersing males and social groups in long-tailed macaques (Macaca fascicularis). Proceedings: Biological Sciences 265:79-87

Divis PC, Singh B, Anderios F, Hisam S, Matusop A, Kocken CH, Assefa SA, Duffy CW, Conway DJ (2015) Admixture in Humans of Two Divergent Plasmodium knowlesi Populations Associated with Different Macaque Host Species. PLoS Pathog 11:e1004888

Fooden, J. 1995. 'Systematic Review of Southeast Asian Longtail Macaques Macaca fascicularis', Fieldiana, 81. 
Fornace, K. M., L. Herman, T. R. Abidin, T. H. Chua, S Daim, P.J. Lorenzo, N. A. Nuin, L. T. Ying, M. J. Grigg, T. William, F. Espino, J. Cox, K. Tetteh, and C. J. Drakeley. in press. 'Exposure and infection to Plasmodium knowlesi in case study communities in Northern Sabah, Malaysia and Palawan, the Philippines', PLoS Negl Trop Dis.

Fornace KM, Abidin TR, Alexander N, Brock P, Grigg MJ, Murphy A, William T, Menon J, Drakeley CJ, Cox J (2016) Association between Landscape Factors and Spatial Patterns of Plasmodium knowlesi Infections in Sabah, Malaysia. Emerg Infect Dis 22:201-209

Fuentes Agustin (2011) Monkeys on the edge: ecology and management of long-tailed macaques and their interface with humans, Cambridge: Cambridge University Press

Grigg MJ, Cox J, William T, Jelip J, Fornace KM, Brock PM, Von Seidlein L, Barber BE, Anstey NM, Yeo TW, Drakeley CJ (2017) Individual-level factors associated with the risk of acquiring human Plasmodium knowlesi malaria in Malaysia: a case control study. Lancet Planetary Health 1:e97-e104

Gumert MD (2011) The common monkey of Southeast Asia: long-tailed macaque populations, ethnophoresy and their occurence in human environments. In: Monkeys on the edge: ecology and management of long-tailed macaques and their interface with humans, Fuentes Agustin (editor), Cambridge: Cambridge University Press

Holmes SM, Gordon AD, Louis EE, Johnson SE (2016) Fissionfusion dynamics in black-and-white ruffed lemurs may facilitate both feeding strategies and communal care of infants in a spatially and temporally variable environment. Behavioral Ecology and Sociobiology 70:1949-1960

Imai N, White MT, Ghani AC, Drakeley CJ (2014) Transmission and control of Plasmodium knowlesi: a mathematical modelling study. PLoS Negl Trop Dis 8:e2978

Janson CH, Byrne R (2007) What wild primates know about resources: opening up the black box. Animal Cognition 10:357367

Johns AD (1986) Effects of selective logging on behavioral ecology of West Malaysian primates. Ecology 67:684-694

Lambin EF, Tran A, Vanwambeke SO, Linard C, Soti V (2010) Pathogenic landscapes: interactions between land, people, disease vectors, and their animal hosts. Int J Health Geogr 9:54

Lee KS, Divis PC, Zakaria SK, Matusop A, Julin RA, Conway DJ, Cox-Singh J, Singh B (2011) Plasmodium knowlesi: reservoir hosts and tracking the emergence in humans and macaques. PLoS Pathog 7:e1002015

Manin BO, Ferguson HM, Vythilingam I, Fornace K, William T, Torr SJ, Drakeley C, Chua TH (2016) Investigating the Contribution of Peri-domestic Transmission to Risk of Zoonotic Malaria Infection in Humans. PLoS Negl Trop Dis 10:e005064

McLean KA, Trainor AM, Asner GP, Crofoot MC, Hopkins ME, Campbell CJ, Martin RE, Knapp DE, Jansen PA (2016) Movement patterns of three arboreal primates in a Neotropical moist forest explained by LiDAR-estimated canopy structure. Landscape Ecol 31:1849-1862

Menard N (2004) Do ecological factors explain the variation in social organisation? Macaque societies: a model for the study of social organisation, Cambridge: Cambridge University Press

Milton K, May ML (1976) Body weight, home range and diet in primates. Nature 259:459-462
Moyes CL, Shearer FM, Huang Z, Wiebe A, Gibson HS, Nijman V, Mohd-Azlan J, Brodie JF, Malaivijitnond S, Linkie M, Samejima H, O’Brien TG, Trainor CR, Hamada Y, Giordano AJ, Kinnaird MF, Elyazar IR, Sinka ME, Vythilingam I, Bangs MJ, Pigott DM, Weiss DJ, Golding N, Hay SI (2016) Predicting the geographical distributions of the macaque hosts and mosquito vectors of Plasmodium knowlesi malaria in forested and nonforested areas. Parasit Vectors 9:242

Nunn CL, Altizer SM (2006) Infectious diseases in primates: behavior, ecology and evolution, Oxford: Oxford University Press

Patz JA, Daszak P, Tabor GM, Aguirre AA, Pearl M, Epstein J, Wolfe ND, Kilpatrick AM, Foufopoulos J, Molyneux D, Bradley DJChange Working Group on Land Use, and Emergence Disease (2004) Unhealthy landscapes: Policy recommendations on land use change and infectious disease emergence. Environ Health Perspect 112:1092-1098

Ren B, Li M, Long Y, Wu R, Wei F (2009) Home range and seasonality of Yunnan snub-nosed monkeys. Integr Zool 4:162171

Rodrigues MA (2017) Female Spider Monkeys (Ateles geoffroyi) Cope with Anthropogenic Disturbance Through Fission - Fusion Dynamics. International Journal of Primatology 38:838-855

Sha JCM, Gumert MD, Lee BPYH, Fuentes A, Rajathurai S, Chan ST, Jones-Engel L (2009) Status of the long-tailed macaque Macaca fascicularis in Singapore and implications for management. Biodiversity and Conservation 18:2909-2926

Shearer FM, Huang Z, Weiss DJ, Wiebe A, Gibson HS, Battle KE, Pigott DM, Brady OJ, Putaporntip C, Jongwutiwes S, Lau YL, Manske M, Amato R, Elyazar IR, Vythilingam I, Bhatt S, Gething PW, Singh B, Golding N, Hay SI, Moyes CL (2016) Estimating Geographical Variation in the Risk of Zoonotic Plasmodium knowlesi Infection in Countries Eliminating Malaria. PLoS Negl Trop Dis 10:e0004915

Singh B, Kim Sung L, Matusop A, Radhakrishnan A, Shamsul SS, Cox-Singh J, Thomas A, Conway DJ (2004) A large focus of naturally acquired Plasmodium knowlesi infections in human beings. Lancet 363:1017-1024

Stark DJ, Vaughan IP, Ramirez Saldivar DA, Nathan SK, Goossens B (2017) Evaluating methods for estimating home ranges using GPS collars: A comparison using proboscis monkeys (Nasalis larvatus). PLoS One 12:e0174891

Unwin S, Ancrenaz M, Bailey W (2011) Handling, anaesthesia, health evaluation and biological sampling. In: Field and laboratory methods in primatology: A practical guide, Setchell JM, Curtis DJ (editors), 2nd ed. Cambridge: Cambridge University Press, pp 147-168

William T, Rahman HA, Jelip J, Ibrahim MY, Menon J, Grigg MJ, Yeo TW, Anstey NM, Barber BE (2013) Increasing incidence of Plasmodium knowlesi malaria following control of P. falciparum and P. vivax Malaria in Sabah, Malaysia. PLoS Negl Trop Dis 7:e2026

Wong ML, Chua TH, Leong CS, Khaw LT, Fornace K, WanSulaiman WY, William T, Drakeley C, Ferguson HM, Vythilingam I (2015) Seasonal and Spatial Dynamics of the Primary Vector of Plasmodium knowlesi within a Major Transmission Focus in Sabah, Malaysia. PLoS Negl Trop Dis 9:e0004135

Young H, Griffin RH, Wood CL, Nunn CL (2013) Does habitat disturbance increase infectious disease risk for primates? Ecol Lett 16:656-663 